\title{
Repair of the sellar floor using bioresorbable polydioxanone foils after endoscopic endonasal pituitary surgery
}

\author{
Jan-Philip Zeden, MD, Jörg Baldauf, MD, and Henry W. S. Schroeder, MD, PhD \\ Department of Neurosurgery, University Medicine Greifswald, Germany
}

OBJECTIVE Postoperative CSF leakage is the most common unwanted sequela of transnasal pituitary surgery. The individual anatomy, the extent of the sellar opening, and the occurrence of an intraoperative CSF leak add to the risk of postoperative rhinorrhea. Despite the current sophistication and recent developments in pituitary surgery, watertight closure of the sellar floor remains a matter of concern. Improvements and additions to the technical armamentarium of sellar reconstruction are therefore still desirable.

METHODS The authors present a closure technique of the sellar floor using a bioresorbable polydioxanone foil, which is placed between the dura and the bony margins of the open sellar floor to keep the intrasellar implants in place and to withstand the pressure arising from the intracranial compartment.

RESULTS The technique was used in a technical case series of 30 patients, and in all patients the floor could be sufficiently reconstructed. CSF flow intraoperatively was documented in 10 cases (33.3\%). Postoperative CSF rhinorrhea was detected in one patient (3.3\%). No complications could be attributed to the technique or the material during a mean follow-up period of 477 days. The foils can easily be identified on MR images and CT scans and therefore do not affect the postoperative radiological assessment.

CONCLUSIONS The described technique is an easy, inexpensive, and reliable method for sellar floor reconstruction and has a low CSF leakage rate. It is recommended when the risk of a postoperative CSF leak is high and there is still enough bony margin of the sellar floor left that enables a sufficient fixation of the foil.

https://thejns.org/doi/abs/10.3171/2020.3.FOCUS2064

KEYWORDS cerebrospinal fluid leak; sellar floor; polydioxanone; endoscopic; transnasal; transsphenoidal; skull base; reconstruction

$\mathrm{P}$ OSTOPERATIVE CSF fistulas remain a common complication of the transnasal route to the cranial base, despite the current sophistication of reconstruction techniques. ${ }^{5}$ The aims of sellar floor reconstruction are the creation of a stable and watertight separation between the intracranial and sinonasal cavities and the best possible preservation or restoration of sinonasal physiology. CSF leaks due to insufficient closure can lead to a symptomatic pneumocephalus and meningitis, posing a potential threat to the patient's life.

While floor reconstruction is mostly not necessary after removal of intrasellar microadenomas when no intraopera- tive CSF flow occurred, floor repair is indicated in most suprasellar macroadenomas, especially when the diaphragm is very thin or when CSF flow was observed during the adenoma resection. Several techniques of sellar floor repair have been recommended. ${ }^{5,8,12}$ The arsenal of existing reconstruction techniques and materials include reconstructions with autologous materials such as bone, fat, fascia, or mucosa. ${ }^{5,18,19}$ While autologous materials are very reliable in preventing CSF leakage, harvesting of these tissue transplants adds complication-related risks and additional postoperative discomfort to the patient, in addition to increased operating room time and costs. Therefore, various

ABBREVIATIONS PDS = polydioxanone. 
other heterologous materials or allografts have been recommended..$^{10,14,20}$

In this report, we describe a technique of using rigid but bendable bioresorbable polydioxanone (PDS) foils for a rapid and rigid reconstruction of the sellar floor after endoscopic endonasal pituitary surgery and analyze the feasibility, outcome, and limitations of this technique in a series of 30 patients.

\section{Methods \\ Patient Population}

The study group consisted of 30 consecutive patients with suprasellar expanding/localized lesions that required closure of the sellar floor post-procedurally. The technique was applied in cases with intraoperative CSF flow and independently of intraoperative CSF flow when the diaphragm was thin and bulging into the sellar space. Between December 2012 and September 2016 in the neurosurgical department of a university clinic in Germany, all patients underwent endoscopic endonasal surgery with reconstruction of the sellar floor by the use of PDS foil (Ethicon). The pathologies consisted of 25 pituitary macroadenomas and 5 Rathke cysts. The size of the study group was determined by the number of cases with the given criteria during the study period. Patient consent for all methods of sellar reconstruction was obtained preoperatively. The study protocol was approved by the local ethics committee.

Operative and follow-up clinical documentation, imaging, and videos were reviewed for demographic data, tumor pathology, tumor or cyst size, materials used for sellar floor reconstruction, intraoperative CSF leakage and grade, postoperative CSF fistula, immediate complications in the postoperative hospital course, and long-term complications.

Lesion sizes were measured on MR images in two planes: midsagittal and coronal. The maximum diameters were documented.

Intraoperative findings were categorized into either no CSF leak (-), CSF flow recognizable upon Valsalva maneuver (+), spontaneous CSF flow (++), or high-flow leak/ torn diaphragm $(+++)$.

Postoperative CSF leaks were determined by positive beta-trace protein tests upon clinical evidence of CSF rhinorrhea. All procedures were performed by the senior author (H.W.S.S.). The patients were examined in an outpatient setting. Follow-up MRI was performed after 3 months postoperatively and annually thereafter. The data are summarized in Table 1.

\section{Sellar Floor Reconstruction With PDS Foils}

PDS foils (Ethicon) are available in various sizes and thicknesses. In addition, the material can be fashioned to the required shape with scissors and can be bent for intranasal application if necessary. The material is degraded by hydrolysis and is completely resorbed. The absorption is complete after about 180 days. PDS still maintains half of its structural strength after 4 weeks. ${ }^{11}$

After evacuation of the Rathke cyst or resection of the adenoma and meticulous hemostasis, the empty sella was filled with gelatin foam, collagen matrix, oxidized cellulose, or an abdominal fat graft. Gelatin foam was used when no CSF flow had been recognized during the resection and the diaphragm was thick (nontranslucent). Collagen matrix was used when minor CSF flow was seen and/or the diaphragm was thin. A fat graft was introduced into the sellar cavity when a major CSF leak had been apparent (tear of more than $1 \mathrm{~mm}$ ). Fibrin glue was applied to fix the collagen matrix and the fat graft. For the reconstruction of the sellar floor, a PDS foil was cut to a size where it would overlap the bony opening at all margins for around $1-2 \mathrm{~mm}$. The foil was then placed in a slightly bent fashion beneath the bony edges of the sellar floor in the epidural space (Figs. 1 and 2, Video 1).

VIDEO 1. Case demonstration. Exemplary case for demonstrating the implantation of a PDS foil. Copyright Jan-Philip Zeden.

Published with permission. Click here to view.

\section{Results}

We used this technique in 30 patients, including 25 patients harboring macroadenomas and 5 patients with Rathke cysts. The patient demographics, tumor characteristics, any adjunctive techniques, and intra- and postoperative CSF leak status are listed in Table 1. The mean patient age was 55.2 years (range 16-80 years), and the female/ male ratio was 17:13.

All cases could be managed using the described technique. CSF flow intraoperatively was documented in 10 cases (33.3\%). Postoperative CSF rhinorrhea was detected in one patient with a Rathke cyst (3.3\%), although intraoperatively no CSF flow had been observed, even after the Valsalva maneuver. MRI showed displacement of the fat graft and the PDS foil into the sphenoid sinus. A surgical revision was performed to reposition the fat graft into the sellar space and reconstruct the sellar floor with a larger PDS foil. MR images obtained 2 days and 3 months after surgery confirmed the successful reconstruction. No CSF leakage occurred. In this series, no infection or meningitis was observed. There were no delayed CSF leaks over a mean follow-up of 15.7 months.

The position of the implant can be identified as a missing intensity signal on postoperative MR images (Fig. 3).

\section{Discussion}

There are numerous reconstruction techniques of the sellar floor after transnasal pituitary surgery. The large number of developed techniques illustrate the importance of a safe and watertight closure postoperatively. With the adaptation of the endoscopic technique, few of the rigid reconstruction techniques have been evaluated and transferred. Thus, the filling of the dead space in the sella after pituitary surgery with the aid of various materials such as collagen matrix, fibrin glue, and other materials is undisputed. The packing of the sphenoid sinus with abdominal fat and the transposition of nasal mucosa as a nasoseptal flap on the cranial base to cover complex defects are also established techniques. ${ }^{5,8}$ The rates of CSF leaks after microsurgical and endoscopic transnasal surgery have so far not been compared in prospective and randomized studies 
TABLE 1. Patient demographics and tumor characteristics, adjunctive measures for the filling of the sellar cavity, and intraoperatively documented CSF flow and postoperative CSF rhinorrhea

\begin{tabular}{|c|c|c|c|c|c|c|c|c|c|c|}
\hline \multirow[b]{2}{*}{ Case No. } & \multirow[b]{2}{*}{ Sex } & \multirow[b]{2}{*}{ Age (yrs) } & \multirow[b]{2}{*}{ Diagnosis } & \multirow[b]{2}{*}{ Follow-Up (days) } & \multicolumn{3}{|c|}{ Tumor Size (mm) } & \multirow[b]{2}{*}{ Adjunctive Measures } & \multirow[b]{2}{*}{ CSF Leak* } & \multirow[b]{2}{*}{ CSF Fistula } \\
\hline & & & & & Height & Width & $\mathrm{AP}$ & & & \\
\hline 1 & M & 60 & Macroadenoma & 2026 & 16 & 12 & 12 & GS & - & No \\
\hline 2 & M & 34 & Macroadenoma & 806 & 8 & 26 & 15 & GS, CM & - & No \\
\hline 3 & M & 53 & Rathke cleft cyst & 1593 & 11 & 11 & 10 & GS & - & No \\
\hline 4 & $M$ & 80 & Macroadenoma & 425 & 31 & 20 & 22 & GS & - & No \\
\hline 5 & $\mathrm{M}$ & 73 & Macroadenoma & 1098 & 22 & 15 & 18 & $\mathrm{FG}, \mathrm{CM}$ & ++ & No \\
\hline 6 & M & 41 & Rathke cleft cyst & 344 & 13 & 13 & 14 & $F, F G$ & - & Yes \\
\hline 7 & $\mathrm{~F}$ & 73 & Rathke cleft cyst & 981 & 14 & 12 & 10 & $\mathrm{CM}$ & - & No \\
\hline 8 & $\mathrm{~F}$ & 67 & Macroadenoma & 85 & 23 & 20 & 18 & $F, F G$ & ++ & No \\
\hline 9 & $\mathrm{~F}$ & 41 & Macroadenoma & 1085 & 10 & 12 & 11 & $F, F G$ & ++ & No \\
\hline 10 & $\mathrm{M}$ & 59 & Macroadenoma & 187 & 24 & 28 & 22 & GS & - & No \\
\hline 11 & $\mathrm{~F}$ & 40 & Macroadenoma & 928 & 14 & 24 & 27 & GS, CM & - & No \\
\hline 12 & $\mathrm{~F}$ & 52 & Macroadenoma & 775 & 22 & 18 & 14 & GM & + & No \\
\hline 13 & $\mathrm{~F}$ & 41 & Macroadenoma & 701 & 28 & 25 & 19 & $\mathrm{CM}$ & - & No \\
\hline 14 & $F$ & 69 & Macroadenoma & 517 & 31 & 28 & 21 & $\mathrm{~F}$ & - & No \\
\hline 15 & $\mathrm{~F}$ & 38 & Macroadenoma & 622 & 26 & 18 & 18 & $\mathrm{~F}, \mathrm{OC}$ & - & No \\
\hline 16 & M & 67 & Macroadenoma & 511 & 25 & 24 & 16 & $\mathrm{CM}$ & - & No \\
\hline 17 & $\mathrm{~F}$ & 63 & Macroadenoma & 99 & 25 & 29 & 22 & GS, FG, OC & - & No \\
\hline 18 & $\mathrm{M}$ & 73 & Macroadenoma & 114 & 37 & 28 & 28 & $\mathrm{GS}, \mathrm{FG}, \mathrm{CM}, \mathrm{OC}$ & - & No \\
\hline 19 & $\mathrm{~F}$ & 45 & Macroadenoma & 114 & 33 & 32 & 20 & $\mathrm{FG}, \mathrm{OC}$ & - & No \\
\hline 20 & $\mathrm{~F}$ & 48 & Macroadenoma & 117 & 21 & 20 & 15 & GS & - & No \\
\hline 21 & $\mathrm{M}$ & 75 & Macroadenoma & 128 & 36 & 25 & 25 & $\mathrm{GS}, \mathrm{FG}, \mathrm{CM}, \mathrm{OC}$ & ++ & No \\
\hline 22 & $M$ & 79 & Macroadenoma & 125 & 40 & 29 & 28 & $\mathrm{GS}, \mathrm{FG}, \mathrm{CM}, \mathrm{OC}$ & ++ & No \\
\hline 23 & $\mathrm{~F}$ & 52 & Macroadenoma & 252 & 36 & 21 & 21 & $\mathrm{~F}, \mathrm{FG}, \mathrm{OC}$ & - & No \\
\hline 24 & $\mathrm{M}$ & 21 & Rathke cleft cyst & 127 & 26 & 24 & 20 & F, FG, OC & - & No \\
\hline 25 & $\mathrm{~F}$ & 52 & Rathke cleft cyst & 127 & 20 & 18 & 13 & GS, F, FG, OC & +++ & No \\
\hline 26 & $\mathrm{~F}$ & 79 & Macroadenoma & 118 & 33 & 20 & 18 & F, FG, OC & ++ & No \\
\hline 27 & $\mathrm{M}$ & 59 & Macroadenoma & 143 & 24 & 28 & 18 & $\mathrm{GS}, \mathrm{F}, \mathrm{FG}, \mathrm{OC}$ & + & No \\
\hline 28 & $\mathrm{~F}$ & 43 & Macroadenoma & 303 & 26 & 26 & 20 & GS, CM & - & No \\
\hline 29 & $\mathrm{~F}$ & 16 & Macroadenoma & 86 & 17 & 22 & 15 & GS & - & No \\
\hline 30 & $\mathrm{~F}$ & 63 & Macroadenoma & 113 & 25 & 22 & 18 & $\mathrm{FG}, \mathrm{CM}, \mathrm{OC}$ & ++ & No \\
\hline
\end{tabular}

$\mathrm{AP}=$ anteroposterior; $\mathrm{CM}=$ collagen matrix; $\mathrm{F}=$ fat graft; $\mathrm{FG}=$ fibrin glue; $\mathrm{GS}$ = gelatin sponge; $\mathrm{OC}=$ oxidized cellulose.

* - = no CSF leak; + = CSF flow upon Valsalva maneuver; ++ = low-flow spontaneous leak; +++ = high-flow leak, opened diaphragm.

but appear to be comparable in the available large clinical series $^{4,9}$ and meta-analyses. ${ }^{1,7,13,15}$

Despite the fact that the published rates of postoperative CSF leaks are low, they remain problematic due to their potentially serious consequences, and technical developments to avoid this complication are desirable.

The reconstruction of the sellar floor is not considered to be necessary in all cases by most authors. The criteria that should lead to additional measures of reconstruction are not precisely defined and essentially derive from the risk factors for the occurrence of postoperative CSF leaks. These include larger and more complex lesions such as macroadenomas, the occurrence of an intraoperative CSF leak, or a postoperative increase in intracranial pressure. .,6,16,17 $^{-1}$

Apart from the known risk factors, there are further observations that were taken as an argument to opt for a rigid reconstruction of the sellar floor. In the literature, there are case descriptions of dislocations of the intrasellarly placed packing material into the sphenoid sinus with a bulging of the diaphragm into the pathologically enlarged empty sella. These observations were associated with postoperative visual loss. ${ }^{6}$ Visual losses were also observed after herniations of the optic chiasm into an empty sella after drug-treated prolactinomas. ${ }^{21}$

In our series, one postoperative CSF leak was observed. On postoperative imaging, a bulging of the diaphragm into the sella with a dislocation of the intrasellarly placed packing material was documented. Reconstruction was repeated successfully by the same technique with the use of a PDS foil of a larger size. We therefore consider a learning process during the adoption of the technique. Others have also recognized dislocation of packing material as a cause for postoperative CSF rhinorrhea 


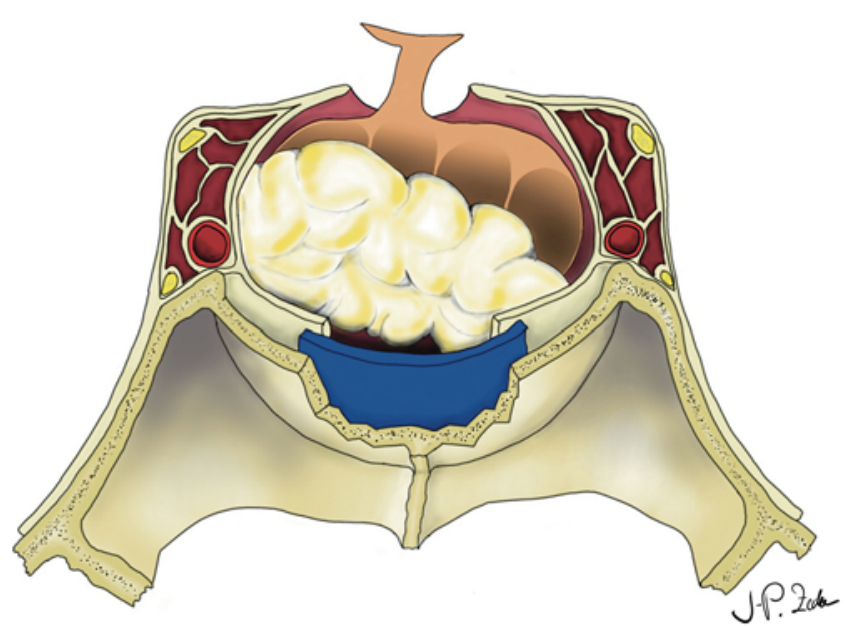

FIG. 1. Schematic illustration in the coronal projection of the sellar region after removal of a pituitary lesion, depicting the placement of the PDS foil placed between the bony sellar floor and the dura. Copyright Jan-Philip Zeden. Published with permission.

and have consequently established a rigid reconstruction technique..$^{5,10,14}$ Magro et al. have been able to achieve a $75 \%$ reduction in postoperative CSF leakages through a rigid reconstruction of the sella. ${ }^{14}$ Cappabianca et al. used a polyester-silicone dural substitute in 15 patients with no postoperative CSF leaks. ${ }^{5}$ Reports on such observations in microsurgical technique do not exist. A combination of intracranial pressure increase due to unintentional Valsalva maneuvers such as sneezing or coughing in the postoperative course with the significantly larger openings of the sellar floor in the endoscopic technique are considered to be the cause of these occasional dislocations. For addressing larger and more complex lesions with the endoscopic technique, larger openings are necessary to accommodate an angled endoscope together with two angulated instruments for bimanual dissection techniques. A larger opening provides less resistance to forces acting on the packing material placed in the resection cavity.

In view of this observation, we have seen the need for a rigid abutment against the dislocation of the packing material as part of the reconstruction of the sellar floor. Therefore, we have developed the technique of inserting absorbable rigid PDS foils behind the bony edges of the open sellar floor. The PDS foil was developed as a carrier and support material and is widely used for reconstruction of orbit fractures and for supporting constructs of the nasal dorsum in reconstructions and corrections of the nasal septum. ${ }^{2,3}$ The foil combines many attributes of an ideal reconstruction material like resorbability, inert behavior, stability, and artifact-free MRI compatibility. With this fast and inexpensive method, a stable reconstruction without harvesting of autologous grafts, can be achieved. Especially in cases of large macroadenomas, the bony floor is usually thinned out or even perforated by the chronic pressure of the tumor and therefore frequently not available as reconstruction material.

There are several limitations associated with this work, which are particularly associated with the small study group. A larger series is needed to describe the effectiveness and possible complications of the described technique. Furthermore, the technique presented here is limited to the reconstruction of the sellar floor after pituitary surgery. It has not been used in more extended approaches. Another limitation is the lack of a strict protocol for the application of the materials to fill the intrasellar dead space. These were applied individually according to the intraoperative conditions and can therefore influence the results. But nevertheless, we think that this simple reconstruction technique is very useful and of interest to the neurosurgical community.
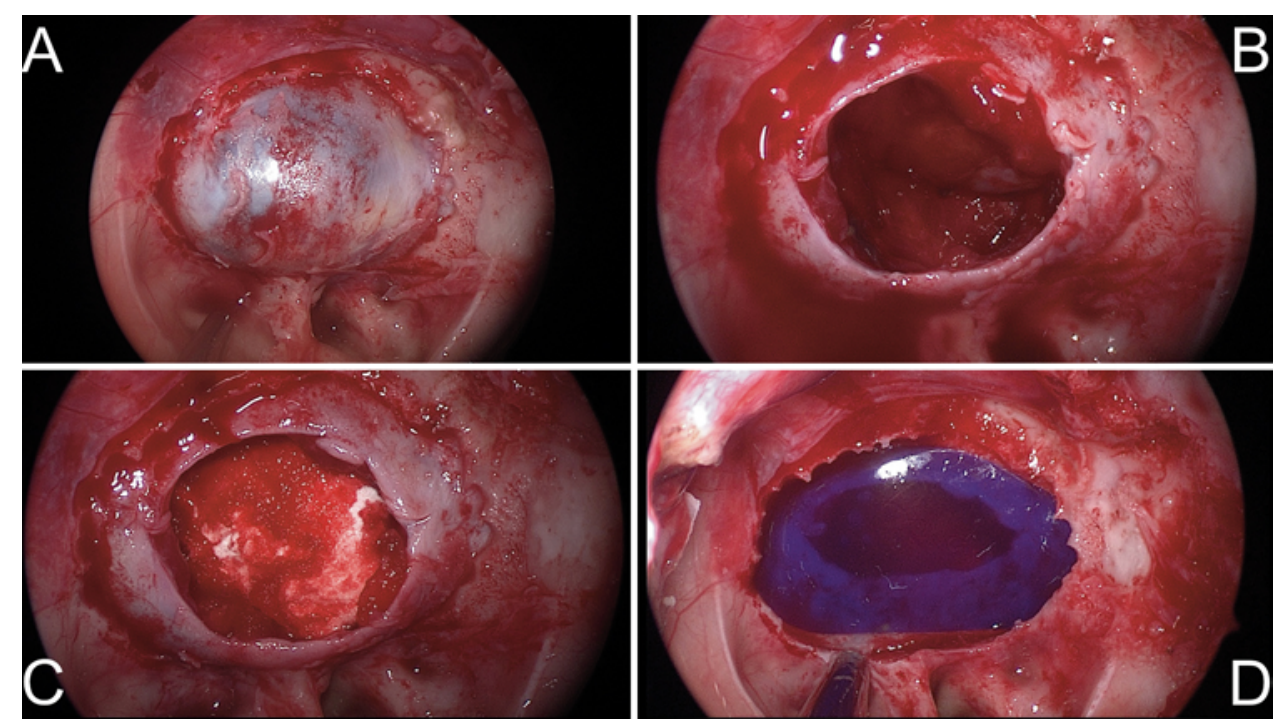

FIG. 2. A: Intraoperative endoscopic view after removal of the bony sellar floor. B: After removal of the tumor, the diaphragm is bulging into the sellar cavity. C: Filled-up dead space of the sellar cavity with gelatin sponge and collagen matrix. D: The PDS foil in place, wedged between the bony ledge and the dura. 

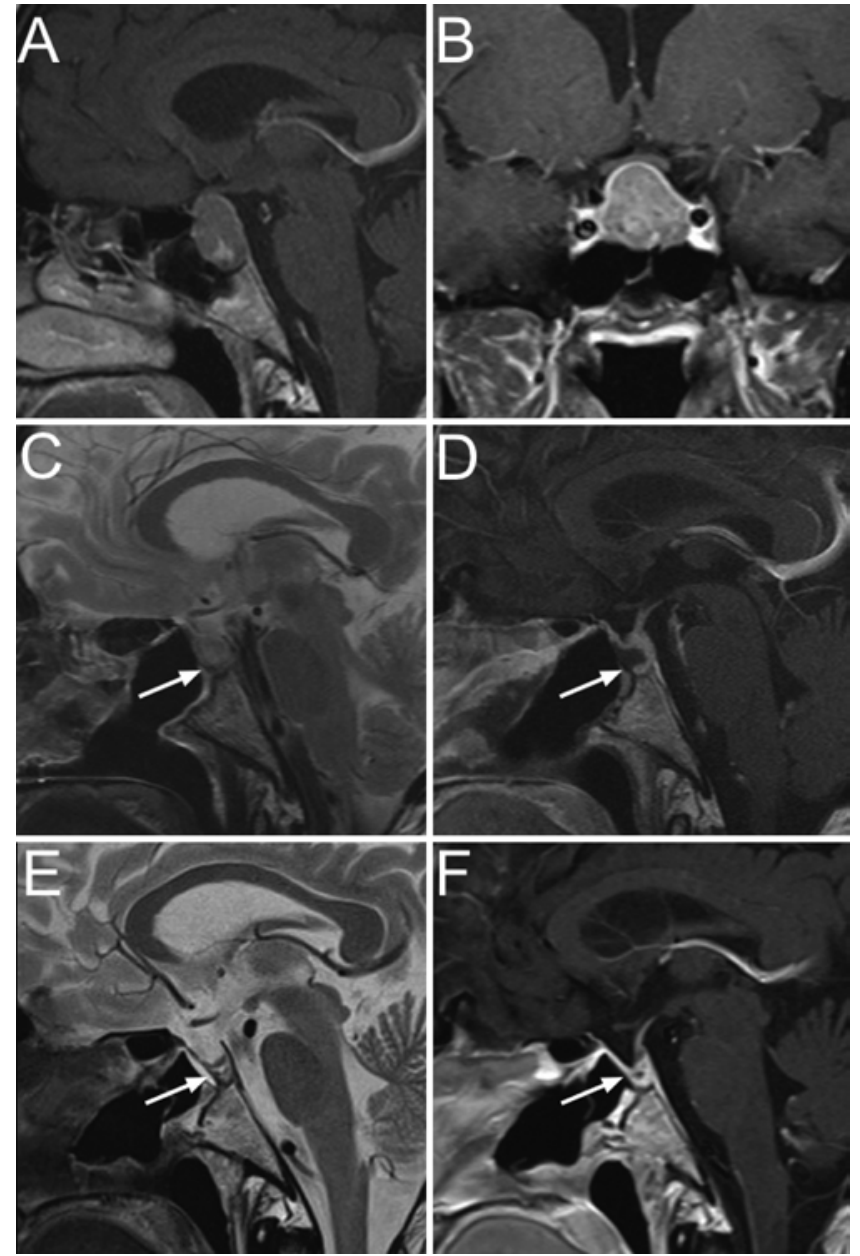

FIG. 3. Illustrative case of a supra- and parasellar macroadenoma. A and B: Images showing the preoperative findings. C and D: Images demonstrating the postoperative situation. In the sagittal plane on the T2-weighted (C) and T1-weighted (D) images, the PDS foil is identifiable as an absent intensity signal (arrows). E and F: Sagittal T2- and T1-weighted MR images acquired 3 months postoperatively showing the PDS foil in place (arrows).

\section{Conclusions}

The described technique is an easy, inexpensive, and reliable method for sellar floor reconstruction. It is recommended when the risk of a postoperative CSF leak is high and there is still enough bony margin around the open sellar floor that enables a sufficient fixation of the foil. Although we only applied this reconstruction method using an endoscopic surgical technique, it can be performed in microsurgical operations as well.

\section{References}

1. Ammirati M, Wei L, Ciric I: Short-term outcome of endoscopic versus microscopic pituitary adenoma surgery: a systematic review and meta-analysis. J Neurol Neurosurg Psychiatry 84:843-849, 2013

2. Beck-Broichsitter BE, Acar C, Kandzia C, Jochens A, Wiltfang J, Becker ST: Reconstruction of the orbital floor with polydioxanone: a long-term clinical survey of up to 12 years. Br J Oral Maxillofac Surg 53:736-740, 2015
3. Boenisch M, Nolst Trenité GJ: Reconstruction of the nasal septum using polydioxanone plate. Arch Facial Plast Surg 12:4-10, 2010

4. Boling CC, Karnezis TT, Baker AB, Lawrence LA, Soler ZM, Vandergrift WA III, et al: Multi-institutional study of risk factors for perioperative morbidity following transnasal endoscopic pituitary adenoma surgery. Int Forum Allergy Rhinol 6:101-107, 2016

5. Cappabianca P, Cavallo LM, Esposito F, Valente V, De Divitiis E: Sellar repair in endoscopic endonasal transsphenoidal surgery: results of 170 cases. Neurosurgery 51:13651372,2002

6. Gondim JA, Almeida JPC, Albuquerque LAF, Schops M, Gomes E, Ferraz T, et al: Endoscopic endonasal approach for pituitary adenoma: surgical complications in 301 patients. Pituitary 14:174-183, 2011

7. Goudakos JK, Markou KD, Georgalas C: Endoscopic versus microscopic trans-sphenoidal pituitary surgery: a systematic review and meta-analysis. Clin Otolaryngol 36:212-220, 2011

8. Hadad G, Bassagasteguy L, Carrau RL, Mataza JC, Kassam A, Snyderman $\mathrm{CH}$, et al: A novel reconstructive technique after endoscopic expanded endonasal approaches: vascular pedicle nasoseptal flap. Laryngoscope 116:1882-1886, 2006

9. Kabil MS, Eby JB, Shahinian HK: Fully endoscopic endonasal vs. transseptal transsphenoidal pituitary surgery. Minim Invasive Neurosurg 48:348-354, 2005

10. Kassam A, Carrau RL, Snyderman CH, Gardner P, Mintz A: Evolution of reconstructive techniques following endoscopic expanded endonasal approaches. Neurosurg Focus 19(1):E8, 2005

11. Kontio R, Ruuttila P, Lindroos L, Suuronen R, Salo A, Lindqvist $\mathrm{C}$, et al: Biodegradable polydioxanone and poly(L/D)lactide implants: an experimental study on peri-implant tissue response. Int J Oral Maxillofac Surg 34:766776,2005

12. Leng LZ, Brown S, Anand VK, Schwartz TH: "Gasket-seal" watertight closure in minimal-access endoscopic cranial base surgery. Neurosurgery 62 (5 Suppl 2):E342-E343, 2008

13. Li A, Liu W, Cao P, Zheng Y, Bu Z, Zhou T: Endoscopic versus microscopic transsphenoidal surgery in the treatment of pituitary adenoma: a systematic review and meta-analysis. World Neurosurg 101:236-246, 2017

14. Magro E, Graillon T, Lassave J, Castinetti F, Boissonneau $\mathrm{S}$, Tabouret E, et al: complications related to the endoscopic endonasal transsphenoidal approach for nonfunctioning pituitary macroadenomas in 300 consecutive patients. World Neurosurg 89:442-453, 2016

15. Rotenberg B, Tam S, Ryu WHA, Duggal N: Microscopic versus endoscopic pituitary surgery: a systematic review. Laryngoscope 120:1292-1297, 2010

16. Seiler RW, Mariani L: Sellar reconstruction with resorbable vicryl patches, gelatin foam, and fibrin glue in transsphenoidal surgery: a 10 -year experience with 376 patients. J Neurosurg 93:762-765, 2000

17. Shiley SG, Limonadi F, Delashaw JB, Barnwell SL, Andersen PE, Hwang PH, et al: Incidence, etiology, and management of cerebrospinal fluid leaks following trans-sphenoidal surgery. Laryngoscope 113:1283-1288, 2003

18. Snyderman CH, Kassam AB, Carrau R, Mintz A: Endoscopic reconstruction of cranial base defects following endonasal skull base surgery. Skull Base 17:73-78, 2007

19. Tabaee A, Anand VK, Brown SM, Lin JW, Schwartz TH: Algorithm for reconstruction after endoscopic pituitary and skull base surgery. Laryngoscope 117:1133-1137, 2007

20. Tabaee A, Kamat A, Shrivastava R: Complex reconstruction of the sella using absorbable mini-plate in revision endoscopic pituitary surgery: technical note. J Neurol Surg A Cent Eur Neurosurg 74:313-317, 2013 
21. Taxel P, Waitzman DM, Harrington JFJ Jr, Fagan RH, Rothfield NF, Chen HH, et al: Chiasmal herniation as a complication of bromocriptine therapy. J Neuroophthalmol 16:252257,1996

\section{Disclosures}

The authors report no conflict of interest concerning the materials or methods used in this study or the findings specified in this paper.

\section{Author Contributions}

Conception and design: Zeden, Schroeder. Acquisition of data: Zeden. Analysis and interpretation of data: Zeden. Drafting the article: Zeden. Critically revising the article: all authors. Reviewed submitted version of manuscript: Baldauf, Schroeder. Statistical analysis: Zeden. Administrative/technical/material support: Baldauf. Study supervision: Schroeder.

\section{Supplemental Information \\ Videos}

Video 1. https://vimeo.com/402133738.

\section{Correspondence}

Jan-Philip Zeden: University Medicine Greifswald, Germany. jpzeden@outlook.com. 